\title{
RESIN POLIURETHAN SEBAGAI BAHAN PELAPISAN AKSESORIS LOGAM UNTUK MENGURANGI CACAT PRODUK BARANG KULIT
}

\author{
Sri Mulati, Agustin Suraswati dan Suprapto
}

INTISARI

Penelitian ini bertujuan untuk mendapatkan teknik pelapisan aksesoris logam pada barang mafit yang tepat tanpa mengurangi keindahan dari aksesoris itu sendiri dan agar aksesoris aitak berubah warna, tidak cepat berkarat untuk menghindarkan atau mengurangi cacat pada bifir. Pelapisan dengan teknik penyemprotan menggunakan alat semprot (spray gun), dilakukan sebanyak 1,2 dan 3 kali masing-masing 3 kali ulangan, terhadap aksesoris logam lapis krom, tupis emas dan bakar. Masing-masing contoh dipasang pada kulit sapi samak krom dan samak whati. Pengujian ketahanan gosok basah dan kering. Analisis data menggunakan Rancangan Acak Lengkap dengan pola faktorial menurut Gasperz (1991), menunjukkan bahwa tidak ata pengaruh yang nyata pada perlakuan pelapisan baik untuk logam lapis krom, lapis emas then bakar yang dipasang pada kulit samak krom dan samak nabati yang sudah disimpan stama 1.2 dan 3 bulan, juga untuk yang belum disimpan. Ada beda nyata yaitu pada aksesoris yang tidak mendapat perlakuan seperti tersebut diatas dan dipasang pada kulit samak nabati ang disimpan selama 3 bulan. Kesimpulan dari penelitian ini adalah bahwa penggunaan poliurethan dengan sistem semprot untuk pelapisan aksesoris logam dapat mempertahankan ienampakan warna (keindahan), membuat tidak berkarat, sehingga tidak menimbulkan cacat pada produk barang kulitnya, baik untuk kulit samak krom maupun samak nabati.

\begin{abstract}
The aim of the research is to aquire an appropriate plating technique on leather product accossories made from metal without lessening the wonderful appearance of the accessories, to maintain the shade and to keep the rust away from the accessories that avoid or diminish deffects on the leather. The plating was carried out by spraying using spraying-gun one, two, and three times, and repeated three times for each treatment to chrome plating metal, gold plaring metal and roasted metal. The samples were then pinned on a piece of chrome tanned learher and vegetable tanned leather, whereas the tests carried out was wet and dry rub fastness. Data analysed using completely randomized design with factorial pattern according to Casperz (1991) showed that there was not significant effect on plating neither metal plated asing chrome, gold, nor roasted metal pinned on chrome and vegetable tanned leather having seen stored for one, two, or three months, neither on similar things having not been stored However there was significant difference on accessories having been do treated as the saned above and set on a piece of vegetable tanned leather stored for three months. Conclusarn could be drawn from the research that the use of polyurethane using spray system for glaring metal accessories was able to maintain its beautiful appearance, keep the rust away, that was not create defects neither on chrome or vegetable tanned leather.
\end{abstract}




\section{PENDAHULUAN}

Aksesoris merupakan komponen kecil yang digunakan pada produk barang kulit untuk menunjang barang kulit supaya nampak indah dan menarik, sehingga mempunyai daya tarik tersendiri dan menjadi produk yang berkualitas dan sesuai apabila dilihat dari segi bentuk, estetika, fungsi, penampilan, mutu bahan, jenis bahan atau jenis peralatan yang digunakan (Bambang Suroto, dkk, 1995).

Sampai saat ini kendala yang dihadapi oleh pengusaha barang kulit terutama pengusaha kecil dan menengah adalah aksesoris yang cepat berubah warna serta berkarat, bahkan ada yang menimbulkan cacat produk pada barang kulitnya. Unt bening, supaya tidak mengurangi melapisi logam aksesoris dengan menggunaktik bening sebagai pelapis untuk kertas, kayu, keindahan dari aksesoris tersebut. Bahan pan resin jenis urethan dan akrilat. Kedua jenis resin logam maupun kulit biasanya menggun plastik, yaitu polimer buatan yang mempunyai sifattersebut diatas merupakan jenis resin plastik, yaitu poli poli isosianat dengan sifat khusus. Resin poliurethan merupakan reaksi sifat lembek digunakan antara lain untuk polyhidroksi material. Poliurethan yang mempunyan dilakukan secara konvensional, baik dengan cat dan pernis. Teknik pelapisan permukaan demprot (spray), yang proses pelapisannya adalah secara fisika menggunakan kuas maupun semini N., dkk, 1994).

Sehubungan dengan hal tersebut perlu kiranya penelitian pelapisan logam aksesoris dengan menggunakan resin poliurethan dilakukan. Penelitian inid cepat berubah warna, tidak mendapatkan teknik pelapisan yang tepat sehingga aksesors tersebut, dan tidak menimbulkan cacat berkarat, tidak mengurangi keind
produk pada barang kulitnya.

\section{MATERI DAN METODE}

Materi :

Kulit sapi samak nabati, kulit sapi samak krom, resin plastik jenis poliurethan (PU) dan macam-macam aksesoris untuk produk kulit yaitu aksesoris lapis krom, lapis emas dan bakar.

Metode :

Pelapisan : Pelapisan dengan bahan resin poliurethan, dengan menggunakan teknik

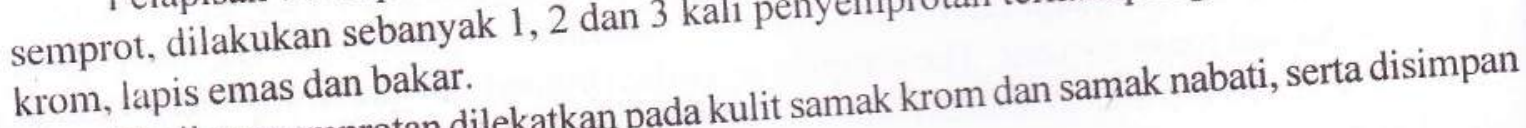

Pengujian sesuai SNI. 06-1389-1989, dilakukan pada akseson 3 bulan. Uji yang dilakukan poliurethan dan masing-masing telah disimpan selama $0,1,2$ dan 3 bak 20 kali, masing-masing adalah uji ketahanan gosok basah dan kering, secara dibandingkan pada skala noda (Staining scale) 3 kali ulangan. Hasil uji dievaluasi dengan dibandituntur) dan nilai 3 (luntur). Pengujian dengan penilaian : nilai 5 (tidak luntur), nilai 4 (sedikit luntur) dan niam sampel.
dilakukan 3 kali pada setiap sak Lengkap (RAL) Data yang didapat dianalisis

dengan pola faktorial menurut Gasperz (1991)
1. Hasil uji k dengan res 1.

Tabel 1. D pelapisan 1

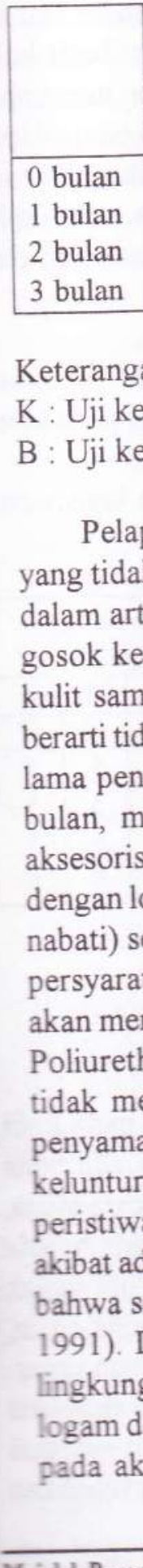

Giluh Barar 


\section{HASIL DAN PEMBAHASAN}

1. Hasil uji ketahanan gosok kering dan basah terhadap aksesoris bakar sesudah pelapisan dengan resin poliurethan pada kulit samak nabati dan samak krom dapat dilihat pada tabel 1 .

Tabel 1. Data rerata ketahanan gosok kering dan basah terhadap aksesoris bakar dengan pelapisan resin poliurethan pada kulit samak nabati dan samak krom.

\begin{tabular}{|c|c|c|c|c|c|c|c|c|c|c|c|c|c|c|c|c|}
\hline & \multicolumn{4}{|c|}{$\begin{array}{c}\text { Tanpa } \\
\text { Pelapisan }\end{array}$} & \multicolumn{4}{|c|}{$\begin{array}{l}\text { Satu kali } \\
\text { Pelapisan }\end{array}$} & \multicolumn{4}{|c|}{$\begin{array}{l}\text { Dua kali } \\
\text { Pelapisan }\end{array}$} & \multicolumn{4}{|c|}{$\begin{array}{l}\text { Tiga kali } \\
\text { Pelapisan }\end{array}$} \\
\hline & \multicolumn{2}{|c|}{ Nabati } & \multicolumn{2}{|c|}{ Krom } & \multicolumn{2}{|c|}{ Nabati } & \multicolumn{2}{|c|}{ Krom } & \multicolumn{2}{|c|}{ Nabati } & \multicolumn{2}{|c|}{ Krom } & \multicolumn{2}{|c|}{ Nabati } & \multicolumn{2}{|c|}{ Krom } \\
\hline & $\mathrm{K}$ & B & $\mathrm{K}$ & B & $\mathrm{K}$ & B & $\mathrm{K}$ & B & $\mathrm{K}$ & B & $\mathrm{K}$ & B & $\mathrm{K}$ & B & $\mathrm{K}$ & B \\
\hline 0 bulan & 5 & 5 & 5 & 5 & 5 & 5 & 5 & 5 & 5 & 5 & 5 & 5 & 5 & 5 & 5 & 5 \\
\hline 1 bulan & 5 & 5 & 5 & 5 & 5 & 5 & 5 & 5 & 5 & 5 & 5 & 5 & 5 & 5 & 5 & 5 \\
\hline 2 bulan & 5 & 5 & 5 & 5 & 5 & 5 & 5 & 5 & 5 & 5 & 5 & 5 & 5 & 5 & 5 & 5 \\
\hline 3 bulan & 4 & 4 & 5 & 5 & 5 & 5 & 5 & 5 & 5 & 5 & 5 & 5 & 5 & 5 & 5 & 5 \\
\hline
\end{tabular}

Keterangan :

$\mathrm{K}$ : Uji ketahanan gosok kering

B : Uji ketahanan gosok basah

Pelapisan kulit dilakukan dengan penyemprotan sebanyak 1, 2 dan 3 kali. Aksesoris yang tidak disemprot digunakan sebagai pembanding, demikian juga yang tidak disimpan dalam arti tanpa perlakuan dan langsung diuji. Dalam tabel 1, terlihat hasil uji ketahanan gosok kering dan basah dari aksesoris bakar lapis poliurethan. Hasil analisis varian pada kulit samak nabati pada hasil uji gosok kering dan basah menunjukkan bahwa $p>0,05$, berarti tidak ada beda nyata pada tiap perlakuan, baik karena pengulangan pelapisan, maupun lama penyimpanan, tetapi pada eksesoris bakar tanpa pelapisan yang disimpan selama 3 bulan, menyebabkan kerusakan pada kulit samak nabati dan sedikit kelunturan dari aksesorisnya (nilai 4). Hal ini disebabkan karena kulit nabati apabila terjadi kontak langsung dengan logam (misalnya besi/Fe), maka logam akan bereaksi dengan tanin (zat penyamak nabati) sehingga akan menimbulkan warna hitam pada kulit. Hal demikian senada dengan persyaratan air untuk penyamakan nabati, tidak boleh mengandung unsur $\mathrm{Fe}$ (besi) karena akan mengakibatkan warna kulit menjadi hitam (tidak cerah). Pada aksesoris yang dilapis Poliurethan baik yang disemprot 1, 2 dan 3 kali dan disimpan selama 1, 2 dan 3 bulan tidak mengalami perubahan warna karena tidak terjadi kontak langsung antar bahan penyamak tanin dengan logam, setelah dilapis dengan resin poliurethan. Selain itu adanya kelunturan warna tersebut dimungkinkan karena terjadinya korosi yang dapat diartikan peristiwa pengkaratan yaitu pengrusakan permukaan logam yang berlangsung sendirinya akibat adanya kontak langsung (interaksi) dengan lingkungan. Hal ini sesuai dengan pendapat bahwa semua logam selain emas dan perak mengalami korosi (Riyanto dan Suwardjono, 1991). Disini poliurethan bertindak sebagai pelindung (protektip) logam dari pengaruh lingkungan dan merupakan salah satu usaha pencegahan terjadinya sifat korosif terhadap logam dengan pemisahan logam dari lingkungan. Oleh karena itu perlu dilakukan pelapisan pada aksesoris yang digunakan pada barang kulit yang dibuat dari kulit samak nabati, 
meskipun hanya satu kali pelapisan, namun manfaat pelapisan ini sudah dapat terlihat, yang terbukti pada penyimpanan 3 bulan tidak terjadi perubahan warna baik pada kulit yang ditempeli maupun pada aksesorisnya.

Pada pelapisan dengan resin poliurethan terhadap aksesoris bakar yang ditempelkan pada kulit samak krom, hasil uji gosok kering dan basah menunjukkan tidak ada beda nyata. Semua aksesoris tidak mengalami kelunturan baik yang dilapisi 1, 2 dan 3 kali penyemprotan dengan poliurethan maupun yang tidak dilapisi. Demikian juga terhadap penyimpanan selama 1, 2 dan 3 bulan tidak menimbulkan cacat pada kulitnya. Hal ini disebabkan karena pada penyamakan kulit dengan bahan penyamak krom, hasil kulit tersamaknya lebih stabil dan tidak mudah terpengaruh oleh logam-logam yang menempel atau melekat, seperti pada kulit samak nabati, misalnya adanya unsur Fe yang dapat menimbulkan warna hitam karena terjadinya reaksi kimia, tetapi pada kulit samak krom reaksi tersebut tidak terjadi, sehingga tidak menimbulkan perubahan warna pada kulit. Pelapisan poliurethan disini juga diperlukan untuk lebih memperindah penampilan dan warna dari aksesorisnya.

2. Hasil uji ketahanan gosok kering dan basah terhadap aksesoris lapis emas sesudah pelapisan dengan resin poliurethan pada kulit samak nabati dan samak krom dapat dilihat pada tabel 2.

Tabel 2. Data rerata ketahanan gosok kering dan basah terhadap aksesoris lapis emas dengan pelapisan resin poliurethan pada kulit samak nabati dan samak krom.

\begin{tabular}{|c|c|c|c|c|c|c|c|c|c|c|c|c|c|c|c|c|}
\hline & \multicolumn{4}{|c|}{$\begin{array}{c}\text { Tanpa } \\
\text { Pelapisan }\end{array}$} & \multicolumn{4}{|c|}{$\begin{array}{l}\text { Satu kali } \\
\text { Pelapisan }\end{array}$} & \multicolumn{4}{|c|}{$\begin{array}{l}\text { Dua kali } \\
\text { Pelapisan }\end{array}$} & \multicolumn{4}{|c|}{$\begin{array}{l}\text { Tiga kali } \\
\text { Pelapisan }\end{array}$} \\
\hline & \multicolumn{2}{|c|}{ Nabati } & \multicolumn{2}{|c|}{ Krom } & \multicolumn{2}{|c|}{ Nabati } & \multicolumn{2}{|c|}{ Krom } & \multicolumn{2}{|c|}{ Nabati } & \multicolumn{2}{|c|}{ Krom } & \multicolumn{2}{|c|}{ Nabati } & \multicolumn{2}{|c|}{ Krom } \\
\hline & $\mathrm{K}$ & B & $\mathrm{K}$ & B & $\mathrm{K}$ & B & $\mathrm{K}$ & B & K & B & $\mathrm{K}$ & B & $\mathrm{K}$ & B & $\mathrm{K}$ & B \\
\hline 0 bulan & 5 & 5 & 5 & 5 & 5 & 5 & 5 & 5 & 5 & 5 & 5 & 5 & 5 & 5 & 5 & 5 \\
\hline 1 bulan & 5 & 5 & 5 & 5 & 5 & 5 & 5 & 5 & 5 & 5 & 5 & 5 & 5 & 5 & 5 & 5 \\
\hline 2 bulan & 5 & 5 & 5 & 5 & 5 & 5 & 5 & 5 & 5 & 5 & 5 & 5 & 5 & 5 & 5 & 5 \\
\hline 3 bulan & 4 & 4 & 5 & 5 & 5 & 5 & 5 & 5 & 5 & 5 & 5 & 5 & 5 & 5 & 5 & 5 \\
\hline
\end{tabular}

Keterangan :

$\mathrm{K}$ : Uji ketahanan gosok kering

B : Uji ketahanan gosok basah

Pada tabel 2 terlihat bahwa hasil uji ketahanan gosok kering dan basah pada kulit samak nabati dan samak krom, sesudah dianalisis varian menunjukkan tidak ada beda nyata, dengan $p>0,05$, yang berarti tidak adanya perubahan/perbedaan warna secara nyata.

Pada aksesoris lapis emas seperti pada aksesoris bakar, perubahan hanya terjadi pada aksesoris lapis emas yang tidak dilapisi dengan poliurethan dan dilekatkan pada kulit samak nabati yang disimpan selama 3 bulan. Hal ini disebabkan karena aksesoris lapis emas, bahan baku aksesoris tersebut tetap dari logam, meskipun dilapisi dengan bahan emas. Pelapisan ini hanya bagian luarnya saja dan lapisan ini sangat tipis, sehingga apabila aksesoris disimpan lama juga akan terjadi korosi dan memungkinkan logam-logam tersebut bereaksi dengan zat penyamak nabati/tanin, menimbulkan warna hitam yang akan menyebabkan 
kerusakan pada kulitnya. Oleh karena itu pelapisan dengan poliurethan sangat diperlukan. Pelapisan ini disamping untuk lebih menambah penampilan agar aksesoris lebih bercahaya juga untuk menahan gesekan pada permukaan barang kulit, sehingga tidak terjadi hubungan langsung antara logam dari aksesoris dengan kulit. Meskipun pelapisan hanya satu kali namun selama penyimpanan tiga bulan tidak terjadi perubahan warna baik pada kulit maupun pada aksesorisnya.

Pada aksesoris lapis emas yang dilapisi maupun yang tidak dilapisi dengan resin poliurethan dan dilekatkan pada kulit samak krom dan disimpan selama 1,2 dan 3 bulan semua aksesoris tidak mengalami perubahan, sehingga tidak menimbulkan cacat pada kulitnya. Hal ini berbeda dengan kulit samak nabati. Kulit jadi samak krom lebih stabil tidak mudah terpengaruh dan mengadakan reaksi dengan logam yang melekat padanya. Hal ini dikarenakan pada proses penyamakan dengan bahan penyamak krom berbeda dengan proses penyamakan dengan bahan penyamak nabati. Disini pelapisan dengan resin poliurethan diperlukan untuk menambah penampilan agar aksesoris lebih bercahaya dan juga lebih tahan terhadap gesekan, sehingga barang kulit akan lebih awet dalam pemakaiannya.

3. Hasil uji ketahanan gosok kering dan basah terhadap aksesoris lapis krom sesudah pelapisan dengan resin poliurethan pada kulit samak nabati dan samak krom dapat dilihat pada tabel 3.

Tabel 3. Data rerata ketahanan gosok kering dan basah terhadap aksesoris lapis krom dengan pelapisan resin poliurethan pada kulit samak nabati dan samak krom.

\begin{tabular}{|c|c|c|c|c|c|c|c|c|c|c|c|c|c|c|c|c|}
\hline & \multicolumn{4}{|c|}{$\begin{array}{c}\text { Tanpa } \\
\text { Pelapisan }\end{array}$} & \multicolumn{4}{|c|}{$\begin{array}{l}\text { Satu kali } \\
\text { Pelapisan }\end{array}$} & \multicolumn{4}{|c|}{$\begin{array}{c}\text { Dua kali } \\
\text { Pelapisan }\end{array}$} & \multicolumn{4}{|c|}{$\begin{array}{l}\text { Tiga kali } \\
\text { Pelapisan }\end{array}$} \\
\hline & \multicolumn{2}{|c|}{ Nabati } & \multicolumn{2}{|c|}{ Krom } & \multicolumn{2}{|c|}{ Nabati } & \multicolumn{2}{|c|}{ Krom } & \multicolumn{2}{|c|}{ Nabati } & \multicolumn{2}{|c|}{ Krom } & \multicolumn{2}{|c|}{ Nabati } & \multicolumn{2}{|c|}{ Krom } \\
\hline & $\mathrm{K}$ & B & $\mathrm{K}$ & B & $\mathrm{K}$ & B & $\mathrm{K}$ & B & $\mathrm{K}$ & B & $\mathrm{K}$ & B & $\mathrm{K}$ & B & $\mathrm{K}$ & B \\
\hline 0 bulan & 5 & 5 & 5 & 5 & 5 & 5 & 5 & 5 & 5 & 5 & 5 & 5 & 5 & 5 & 5 & 5 \\
\hline 1 bulan & 5 & 5 & 5 & 5 & 5 & 5 & 5 & 5 & 5 & 5 & 5 & 5 & 5 & 5 & 5 & 5 \\
\hline 2 bulan & 5 & 5 & 5 & 5 & 5 & 5 & 5 & 5 & 5 & 5 & 5 & 5 & 5 & 5 & 5 & 5 \\
\hline 3 bulan & 4 & 4 & 5 & 5 & 5 & 5 & 5 & 5 & 5 & 5 & 5 & 5 & 5 & 5 & 5 & 5 \\
\hline
\end{tabular}

Keterangan :

$\mathrm{K}$ : Uji ketahanan gosok kering

B : Uji ketahanan gosok basah

Pada tabel 3 terlihat bahwa hasil uji ketahanan gosok kering dan basah pada kulit samak nabati dan samak krom, menunjukkan tidak ada beda nyata, $p>0,05$, berarti tidak ada perbedaan/perubahan warna secara nyata.

Pada aksesoris lapis krom tanpa dilakukan pelapisan dengan resin poliurethan yang ditempelkan pada kulit samak nabati dan disimpan selama 3 bulan, terjadi perubahan warna (nilai). Hal ini disebabkan karena meskipun aksesoris sudah dilapisi dengan krom, yang dimaksudkan untuk melindungi logam aksesoris dari pengaruh lingkungan, namun karena lapisan krom tersebut tipis sehingga aksesoris akan mudah mengalami kerusakan yang diakibatkan adanya korosi dan pengkaratan, yang menimbulkan perubahan warna. 
Selain itu dapat juga terjadi karena lapisan krom adalah unsur logam, maka akan terjadi pula reaksi antara krom dengan zat penyamak nabati (tanin) yang ada dikulit, sehingga akan menimbulkan warna yang akan mengakibatkan adanya cacat pada kulit. Oleh sebab itu pelapisan aksesoris dengan resin poliurethan diperlukan disamping untuk perlindungan dari logam aksesoris juga untuk menambah keindahan. Disini terlihat bahwa pelapisan meskipun hanya satu kali namun sudah cukup karena sudah tidak terjadi perubahan meskipun sudah disimpan selama 3 bulan. Lain dengan aksesoris yang ditempel pada kulit samak nabati, aksesoris yang ditempel pada kulit samak nabati yang tidak dilapisi dengan resin poliurethan menunjukkan adanya kelunturan/perubahan warna setelah disimpan selama 3 bulan, sehingga menimbulkan cacat pada kulit, tetapi yang telah dilapisi 1, 2 dan 3 kali penyemprotan dan disimpan selama 1,2 dan 3 bulan tidak menimbulkan cacat pada kulit dan tidak luntur. Hal ini berbeda dengan kulit samak nabati, pada kulit samak krom lebih stabil dan bahan penyamak krom juga tidak bereaksi dengan aksesoris. Dengan adanya pelapisan resin poliurethan akan menambah perlindungan terhadap gesekan, sehingga aksesoris akan lebih tahan terhadap adanya pengaruh lingkungan yang akan dapat mengurangi timbulnya cacat aksesoris dan akan berdampak pada kulitnya. Selain itu pelapisan dengan resin poliurethan akan membuat aksesoris lebih indah dan bercahaya meskipun pelapisannya hanya satu kali.

\section{KESIMPULAN DAN SARAN}

Kesimpulan dari penelitian ini adalah dengan sistem penyemprotan resin poliurethan terhadap aksesoris logam dapat menambah keindahan dan dapat menghindarkan adanya cacat pada kulit samak nabati dan samak krom yang disebabkan pemakaian aksesoris logam sesudah dalam penyimpanan selam 3 bulan.

Saran yang diajukan adalah resin poliurethan merupakan salah satu resin yang dapat digunakan untuk pelapisan logam aksesoris yang dipasang pada barang kulit nabati maupun krom, cara pelapisan dengan penyemprotan cukup satu kali saja.

\section{DAFTAR PUSTAKA}

Bambang Suroto, Th. Widiarti dan Suramto, 1995, Peranan Disain Dalam Peningkatan Mutu Produk Kulit, Proseding Seminar Sehari Mutu dan Produk Kulit Untuk Ekspor, BBKKP, Yogyakarta.

Dewan Standardisasi Nasional (DSN), 1989, SNI. 06-1289-1989, Cara Uji Kelunturan Warna Pada Kulit Imitasi, Dep. Perindustrian dan Perdagangan, Jakarta.

Dwi Wahini N., Sugiarto D., Pramono, Marsono dan Agustin S., 1994, Penelitian Pelapisan

Kulit Menggunakan Teknologi Radiasi Berkas Elektron, Buletin Sains dan Teknologi, No. 3 Th. III, HAKTKI, Yogyakarta.

Firdaus Ali, 1995, Kebijaksanaan Departemen Perindustrian dan Perdagangan Dalam Meningkatkan Ekspor Kulit Dan Produk Kulit Indonesia, Proseding Seminar Sehari Mutu Kulit dan Produk Kulit Untuk Ekspor, BBKKP, Yogyakarta.

Gasperz, 1991, Metode Perencanaan Percobaan Untuk Ilmu-Ilmu Pertanian, Ilmu-Ilmu Teknik dan Biologi, Armico, Bandung.

Harold Hard, 1983, Organic Chemistry, Hougton Miffin Co. 
JA. Brydson, 1983, Plastic Material, Fourth Edition, Polytechnic of North London, Riyanto dan Suwardjono, 1991, Pelapisan Barang Kerajinan Tembaga dan Kuningan dengan Metode Elektroplating, Majalah Dinamika Kerajinan dan Batik No 9, BBKB, Yogyakarta 